\title{
Reduction-triggered Ligand Dissociation of Trinuclear Complex Bearing Three Kinds of Metal-ligand Units
}

\section{Natsuki Yabune, Ryosuke Monju, Hiroshi Nakajima, Takanori Nishioka}

\begin{tabular}{|c|l|}
\hline Citation & Chemistry Letters. 48(12); 1511-1514- \\
\hline Issue Date & $2019-12-16$ \\
\hline Type & Journal Article \\
\hline Textversion & Author \\
\hline Relation & $\begin{array}{l}\text { The following article has been accepted by Chemistry Letters. The final, published } \\
\text { version is available at https://doi.org/10.1246/cl.190707. }\end{array}$ \\
\hline Rights & $\begin{array}{l}\text { C } 2019 \text { The Chemical Society of Japan. This article may be downloaded for personal } \\
\text { use only. Please cite only the published version. }\end{array}$ \\
\hline DOI & \begin{tabular}{l}
$10.1246 / c l .190707$ \\
\hline
\end{tabular} \\
\hline
\end{tabular}

\author{
Self-Archiving by Author(s) \\ Placed on: Osaka City University
}

YABUNE, N., MONJU, R., NAKAJIMA, H., \& NISHIOKA, T. (2019). Reduction-triggered Ligand Dissociation of Trinuclear Complex Bearing Three Kinds of Metal-ligand Units. Chemistry Letters. 48, 1511-1514. doi:10.1246/cl.190707 


\title{
Reduction-Triggered Ligand Dissociation of Trinuclear Complex Bearing Three Kinds of Metal-Ligand Units
}

\author{
Natsuki Yabune, Ryosuke Monju, Hiroshi Nakajima, and Takanori Nishioka* \\ Department of Chemistry, Graduate School of Science, Osaka City University, Osaka 558-8585
}

E-mail: nishioka@sci.osaka-cu.ac.jp

1 A heterometallic trinuclear complex with three metal2 metal bonds, which is constituted of three kinds of metal3 ligand units bridged by two sulfido ligands, reacts with a 24 electron donor to afford an adduct accompanied with 5 elongation of the metal-metal bonds. Cyclic voltammograms 6 of the complexes showed that the adduct releases the 27 electron donor after electrochemical 1-electron reduction.

8 Keywords: Trinuclear complex, N-Heterocyclic carbene, 9 Sulfide ligand

Trinuclear complexes with 48 cluster valence electrons closed-shell electron configuration of metal centers with three metal-metal bonds. ${ }^{1}$ Even though, some reactions such as substitution ${ }^{2-12}$ and addition ${ }^{13}$ were reported. For example, one carbonyl ligand of $\mathrm{Co}_{2} \mathrm{Fe}$ carbonyl clusters substituted with phosphines or arsines with no change of the CVEs. ${ }^{2-5}$ An $\operatorname{Ir}_{2} \mathrm{M}$ complexes $(\mathrm{M}=\mathrm{Pd}, \mathrm{Pt})$ also showed similar substitution reaction on the Pd or Pt center, of which chloro ligands were substituted with pyridine derivatives ${ }^{6}$ or phosphines. ${ }^{7}$ Successive addition of $\mathrm{CO}$ ligands to a $\mathrm{CrMn}_{2}$ carbonyl clusters resulted in $\mathrm{M}-\mathrm{M}$ bond elongation with CVE changes from 48 to 50 and from 50 to $52 .{ }^{13} \mathrm{~A} \mathrm{Ru}_{3}$ complex with 48 CVEs exhibited reversible thermal activation of a $\mathrm{P}-\mathrm{C}$ bond in one of two $\mathrm{PPh}_{3}$ ligands in the complex. ${ }^{14}$ For a $\mathrm{Co}_{2} \mathrm{Fe}$ carbonyl cluster with a triply bridging sulfido ligand, isolobal displacement reaction with Cr carbonyl complexes with substituted cyclopentadienyl ligands was also reported. ${ }^{15}$

We previously reported trinuclear complexes bearing triply bridging sulfido ligands, $\left[(\mathrm{MCp} *)_{3}\left(\mu_{3}-\mathrm{S}\right)_{2}\right]^{2+}(\mathrm{M}=\mathrm{Rh}$, Ir; $\left.\mathrm{Cp}^{*}=\eta^{5}-\mathrm{C}_{5} \mathrm{Me}_{5}\right){ }^{16}$ The complexes are very stable and reduction of the complexes promotes reaction with $\mathrm{CO}_{2}$ via $\mathrm{M}-\mathrm{M}$ or $\mathrm{M}-\mathrm{S}$ bond cleavage. ${ }^{17-19}$ We also synthesized $\mathrm{M}_{2} \mathrm{M}^{\prime}$ type trinuclear complexes $\left[\left(\mathrm{MCp}^{*}\right)_{2}\{\mathrm{Pt}(\mathrm{bisNHC}-\right.$ $\left.\mathrm{Cn})\}\left(\mu_{3}-\mathrm{S}\right)_{2}\right]^{2+}(\mathrm{M}=\mathrm{Rh}$, Ir; M' $=\mathrm{Pd}$, Pt; bisNHC-Cn $=$ $\left(\mathrm{CH}_{2}\right)_{n}$-bridged bis(N-substituted-imidazolylidene), $\left.n=1-3\right)$ to tune properties of trinuclear complexes by replacement of one of the three $\left\{\mathrm{Cp}^{*} \mathrm{M}\right\}$ moieties in $\left[\left(\mathrm{MCp}^{*}\right)_{3}\left(\mu_{3}-\mathrm{S}\right)_{2}\right]^{2+}$ with one $\left\{\mathrm{M}^{\prime}(\right.$ bisNHC-Cn) $\}$ unit, which are electronically and stereochemically tunable components using variable Nsubstituents and the alkylene bridges. ${ }^{20,21}$ Here, we planned to replace one more $\left\{\mathrm{MCp}^{*}\right\}$ moiety with a $\{\mathrm{Pt}(\mathrm{bpy})\}$ unit and report sequential construction of a (ML)(M'L')(M'L”) type trinuclear complex with triply-bridging sulfido ligands with 48 CVEs. We also describe the reaction of the 48-CVE complex with triethyphosphite as a 2-electron donor affording a complex with 50 CVEs, which releases the phosphite ligand via electrochemical reduction of the complex.
A 48-CVE heterometallic trinuclear complex constituted of three metal-ligand units, $[\{\mathrm{Pt}($ bisNHC $)\}$ $\left.\{\mathrm{Pt}(\mathrm{bpy})\}\left(\mathrm{RhCp}^{*}\right)\left(\mu_{3}-\mathrm{S}\right)_{2}\right]^{2+}\left([\mathbf{2}]^{2+}\right.$, bisNHC = methylenebridged bis(N-methylimidazolylidene)), was synthesized via addition of the $\{\mathrm{Pt}(\mathrm{bpy})\}$ unit to a dinuclear complex $\left[\{\mathrm{Pt}(\mathrm{bisNHC})\}\left\{\mathrm{RhCp}^{*}\left[\mathrm{P}(\mathrm{OEt})_{3}\right]\right\}(\mu-\mathrm{SH})_{2}\right]^{2+}\left([\mathbf{1}]^{2+}\right)$, which was obtained from the reaction of in-situ generated $\left[\mathrm{RhCp} *\left\{\mathrm{P}(\mathrm{OEt})_{3}\right\}(\mathrm{SH})_{2}\right]$ with $\left[\mathrm{Pt}(\text { bisNHC })(\mathrm{NCMe})_{2}\right]^{2+}$. The 48-CVE PtPtRh complex reacts with triethyl phosphite to afford a corresponding 50-CVE adduct, $[\{\mathrm{Pt}($ bisNHC $)\}$ $\left.\{\mathrm{Pt}(\mathrm{bpy})\}\left\{\mathrm{RhCp} *\left[\mathrm{P}(\mathrm{OEt})_{3}\right]\right\}\left(\mu_{3}-\mathrm{S}\right)_{2}\right]^{2+} \quad\left([3]^{2+}\right), \quad$ which releases the phosphite ligand by heating to lead regeneration of the 48-CVE complex (Scheme 1).

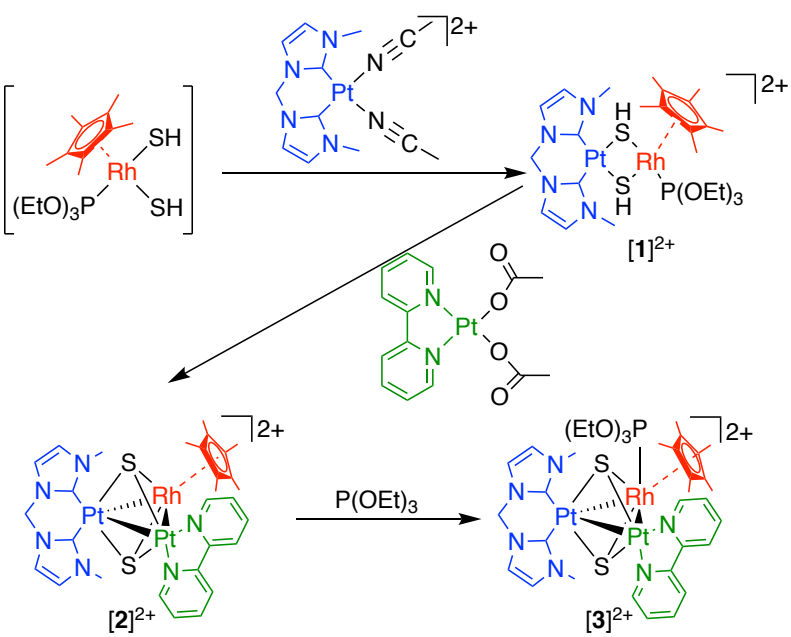

64 Scheme 1. Syntheses of dinuclear and trinuclear complexes

66 Figure 1. Structure of the cationic moiety of the $\mathrm{PF}_{6}$ salt of 48-CVE 67 PtPtRh complex [2] $\left(\mathrm{PF}_{6}\right)_{2}$. Hydrogen atoms are omitted for clarity. 
1

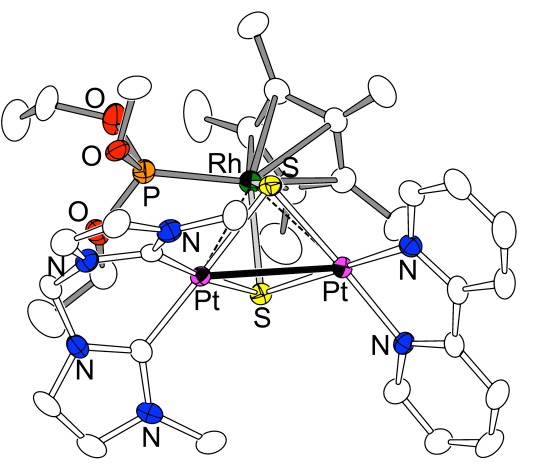

2 Figure 2. Structure of the cationic moiety of the $\mathrm{PF}_{6}$ salt of 50-CVE 3 PtPtRh complex $[3]\left(\mathrm{PF}_{6}\right)_{2}$. Hydrogen atoms are omitted for clarity.

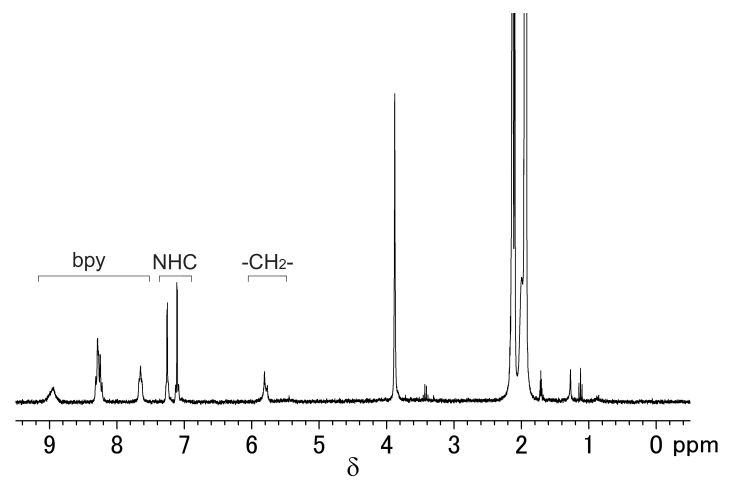

5 Figure 3. ${ }^{1} \mathrm{H}$ NMR spectrum in $\mathrm{CD}_{3} \mathrm{CN}$ for $48-\mathrm{CVE}$ complex $[2]^{2+}$.

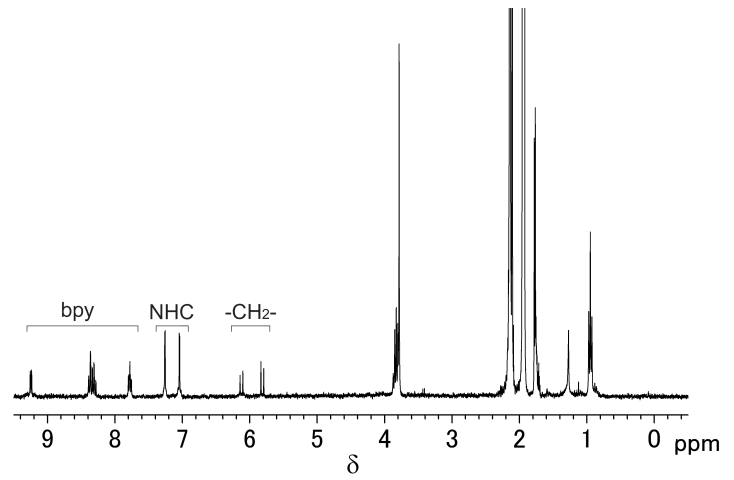

7 Figure $4{ }^{1} \mathrm{H}$ NMR spectrum in $\mathrm{CD}_{3} \mathrm{CN}$ for 50 -CVE complex $[3]^{2+}$.
The structures of the hexafluorophosphate salts of 48and 50-CVE complexes $[2]\left(\mathrm{PF}_{6}\right)_{2}$ and $[3]\left(\mathrm{PF}_{6}\right)_{2}$, respectively, were analyzed by using X-ray crystallography (Figures 1 and 2). ${ }^{22,23}$ In each complex, three metal ions are bridged by two sulfido ligands and two platinum(II) ions adopt square planer geometry when the metal-metal bonds are not taken into account. Complex $[2]^{2+}$ involves formally fivecoordinated rhodium(III) ion with two sulfido and one Cp * ligands, and $[3]^{2+}$ contains formally six-coordinated rhodium(III) ion with piano stool type geometry constituted of one $\mathrm{Cp}^{*}$, two sulfido and one phosphite ligands. Although there are two possible isomers for $[2]^{2+}$ due to the orientation of the bisNHC ligand adopting a bent structure, only one of them was observed in the crystallographic analysis. ${ }^{1} \mathrm{H}$ NMR spectrum of the complex (Figure 3) showed broad signals despite of the diamagnetic nature of the $48-\mathrm{CVE}$ cluster core in $[2]^{2+}$. This broadening of the signals is attributed to the wing-flapping motion of the bisNHC ligand, which was reported for heterometallic $\mathrm{M}_{2} \mathrm{M}^{\prime}$ type trinuclear complexes, $\left[\left(\mathrm{MCp}^{*}\right)_{2}\left\{\mathrm{M}^{\prime}(\right.\right.$ bisNHC$\left.)\right\}$ $\left.\left(\mu_{3}-\mathrm{S}\right)_{2}\right]^{2+}\left(\mathrm{M}=\mathrm{Rh}, \mathrm{Ir} ; \mathrm{M}^{\prime}=\mathrm{Pd}, \mathrm{Pt}\right){ }^{21}$ This means that there are two isomers in solution and one of them crystallizes probably due to the difference in solubility and/or crystal packing effects of the isomers. On the other hand, ${ }^{1} \mathrm{H}$ NMR spectrum of $[3]^{2+}$ (Figure 4) showed only one set of sharp signals for the complex even though there are four possible isomers occurred by the orientation of the bisNHC ligand and location of the phosphite ligand. This result suggests that only one isomer exists in solution. This selective formation of the complex is probably attributed to steric repulsion between the ancillary ligands of the metal-ligand units and the phosphite ligand. The $\mathrm{Rh}-\mathrm{Pt}$ distances significantly elongate by the coordination of the phosphite $\left(\mathrm{Rh}-\mathrm{Pt}_{\mathrm{NHC}}\right.$ and $\mathrm{Rh}-\mathrm{Pt}_{\mathrm{bpy}} ; 2.9985(9)$ and $2.8977(8) \AA$ for $[2]^{2+}$ and $3.3796(6)$ and $3.3326(6) \AA$ for $[3]^{2+}$, respectively) while the Pt-Pt distance shortens (3.204(1) and 2.9970(5) $\AA$ for $[2]^{2+}$ and $[3]^{2+}$, respectively). This fact implies that the bond orders for two of three metal-metal bonds in $[2]^{2+}$ decrease from 1 to 0.5 by the coordination of the twoelectron donor rather than one of the three metal-metal bonds in $[2]^{2+}$ is cleaved via changing CVEs from 48 for $[2]^{2+}$ to 50 for $[3]^{2+}$ by the coordination of the phosphite.

The cyclic voltammogram (CV) for $[2]^{2+}$ (Figure 5, blue line) exhibited two reversible 1-electron reduction/reoxidation couples at $-1.34((\mathrm{a}) /(\mathrm{d}))$ and $-1.80 \mathrm{~V}((\mathrm{~b}) /(\mathrm{c}))$ vs. $\mathrm{Fc}^{+} / \mathrm{Fc}$. DFT calculation of the complex suggested that the reduction occurred at the cluster core (See Supporting Information). Similar redox behavior of 48-CVE trinuclear complexes with triply bridging sulfido ligands were reported for $\left[\{\mathrm{Pt}(\mathrm{bisNHC})\}\left(\mathrm{RhCp}^{*}\right)_{2}\left(\mu_{3}-\mathrm{S}\right)_{2}\right]^{2+}$ and $\left[\left(\mathrm{RhCp}^{*}\right)_{3}\left(\mu_{3^{-}}\right.\right.$ $\left.\mathrm{S}_{2}\right]^{2+}$ showing two reversible redox couples at -1.10 and $1.67 \mathrm{~V}^{16,17}$ and -0.90 and $-1.29 \mathrm{~V}^{20,21}$ respectively. The redox potentials for PtPtRh complex $[2]^{2+}$ are more negative than those observed for the $\mathrm{Rh}_{3}$ and $\mathrm{PtRh}_{2}$ complexes.

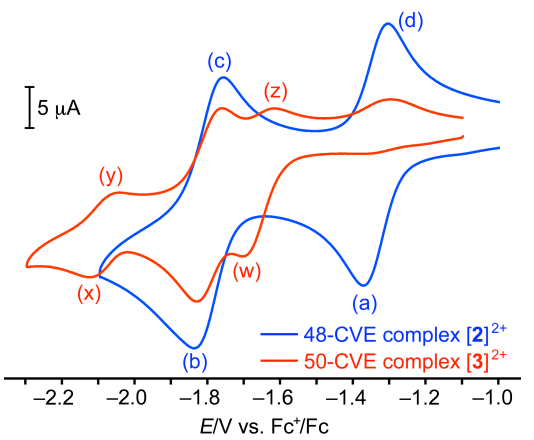

Figure 5. Cyclic voltammograms for $48-\left([2]^{2+}, 0.5 \mathrm{mM}\right.$, blue line) and 50-CVE $\left([3]^{2+}, 0.5 \mathrm{mM}\right.$, red line) PtPtRh complexes. 0.1 M TBAPF 6 in $\mathrm{MeCN}$. Scan rate: $100 \mathrm{mV} / \mathrm{s}$. Working electrode: $\phi 3 \mathrm{~mm}$ glassy carbon.

On the other hand, phosphite-coordinated 50-CVE complex $[3]^{2+}$ showed a complicated voltammogram (Figure 
15 , red line $)$. Other than two quasi-reversible couples $((\mathrm{w}) /(\mathrm{z})$

2 and $(\mathrm{x}) /(\mathrm{y}))$, the $\mathrm{CV}$ exhibited the waves corresponding to 3 the redox processes for 48-CVE complex [2] $]^{2+}($ (b), (c) and

4 (d)) probably due to a subsequent reaction. To confirm such

5 EC process, faster scan rate $(5000 \mathrm{mV} / \mathrm{s})$ was applied for the 6 measurement affording a simple voltammogram showing 7 only the two quasi-reversible couples, $(\mathrm{w}) /(\mathrm{z})$ and $(\mathrm{x}) /(\mathrm{y})$, 8 which correspond to $[3]^{2+/+}$ and $[3]^{+/ 0}$ redox couples, 9 respectively (Figure 6). DFT calculation of the complex 10 implies that the reduction occurred at the $\{\mathrm{Pt}(\mathrm{bpy})\}$ unit 11 (See Supporting Information). The observation of the redox 12 waves (b), (c), and (d) corresponding to the redox series for $13[2]^{2+}$ in the $\mathrm{CV}$ of $[3]^{2+}$ with the slower scan rate (Figure 5, 14 red line) shows that the subsequent reaction gives 15 phosphite-dissociated complex $[2]^{+}$. The appearance of the 16 re-reduction wave (a) in the second cathodic scan in the $\mathrm{CV}$ 17 with repeated scan cycles (Figure 7) also supports the 18 formation of 48-CVE complex $[2]^{2+}$. Ligand-dissociation 19 enhanced by electrochemical reduction was reported for a 20 triiron carbonyl complex with triply bridging sulfido 21 ligands. $^{24}$

23 Figure 6. Cyclic voltammogram for 50-CVE PtPtRh complex ([3] $]^{2+}$, $240.5 \mathrm{mM}$ ). $0.1 \mathrm{M} \mathrm{TBAPF}_{6}$ in MeCN. Scan rate: $5000 \mathrm{mV} / \mathrm{s}$. Working 25 electrode: $\phi 3 \mathrm{~mm}$ glassy carbon.

27 Figure 7. Cyclic voltammograms with repeated scans for 50-CVE 28 complex $[3]^{2+}(0.5 \mathrm{mM}) .0 .1 \mathrm{M} \mathrm{TBAPF}_{6}$ in $\mathrm{MeCN}$. Scan rate: $100 \mathrm{mV} / \mathrm{s}$.

29 Working electrode: $\phi 3 \mathrm{~mm}$ glassy carbon (dashed line: 1 st scan, red 30 line: 2nd scan).

The CV measurement of phosphite-coordinated 32 complex $[3]^{2+}$ in the presence of excess phosphite was also
51 Figure 8. Cyclic voltammogram for 50-CVE complex $\left([3]^{2+}, 0.5 \mathrm{mM}\right)$ 52 in the presence of excess $\mathrm{P}(\mathrm{OEt})_{3} .0 .1 \mathrm{M} \mathrm{TBAPF}_{6}$ in $\mathrm{MeCN}$. Scan rate: 53

for $[3]^{2+/+}$ even the waves (b), (c), and (d) for the redox series of $[2]^{2+}$ were observed. This result implies that 1 electron reduced complex $[3]^{+}$, which partially remained after slow dissociation reaction of the $\mathrm{P}(\mathrm{OEt})_{3}$ ligand in the EC process, would react with excess phosphite and decompose to the other complexes. Observation of the waves (b), (c), and (d) also suggests that the reaction of the phosphite-released 49- and 50-CVE complexes with $\mathrm{P}(\mathrm{OEt})_{3}$ is slow because no re-oxidation wave for the phosphitecoordinated complex was observed. The electrochemical processes described in this paper are summarized in Scheme 2. The labels (a)-(d) and (w)-(z) are corresponding to the redox waves labeled in Figures 5-8.

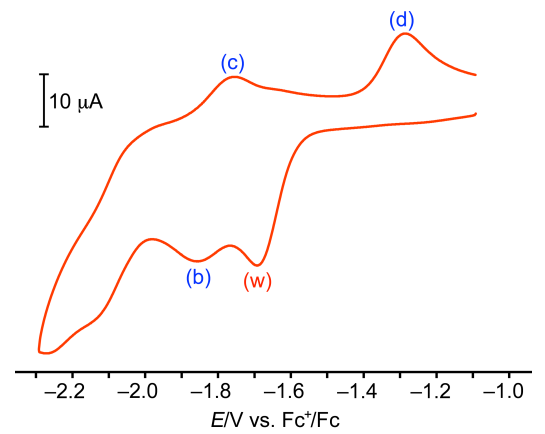

$100 \mathrm{mV} / \mathrm{s}$. Working electrode: $\phi 3 \mathrm{~mm}$ glassy carbon.

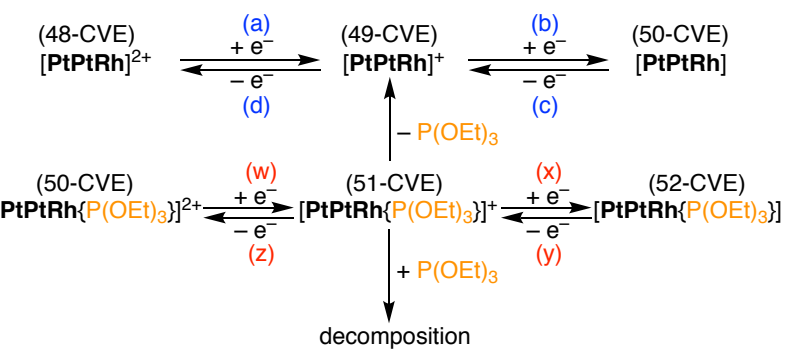

$\{$ PtPtRh $\}=\left\{[\operatorname{Pt}(\right.$ bisNHC) $)][\operatorname{Pt}($ bpy $\left.)]\left(\operatorname{RhCp}^{\star}\right)\left(\mu_{3}-\mathrm{S}\right)_{2}\right\}$

Scheme 2. Electrochemical processes for a redox series of 50- and 48CVE complexes, $[3]^{\prime+}$ and $[2]^{2+}$.

In conclusion, we demonstrated rational synthesis of the 48-CVE PtPtRh heterometallic trinuclear complex constituted of three kinds of metal-ligand units, $\left[\{\mathrm{Pt}(\text { bisNHC })\}\{\mathrm{Pt}(\mathrm{bpy})\}\left(\mathrm{RhCp}^{*}\right)\left(\mu_{3}-\mathrm{S}\right)_{2}\right]^{2+}$, by sequential construction via the PtRh dinuclear complex, [ $\left\{\mathrm{RhCp}^{*}\right.$ $\left.\left[\mathrm{P}(\mathrm{OEt})_{3}\right]\right\}[\mathrm{Pt}($ bisNHC $\left.)](\mu-\mathrm{SH})_{2}\right]^{2+}$, in relatively high total yield. The 48-CVE trinuclear complex, which possesses a five-coordinated $\mathrm{Rh}$ center, readily reacts with triethyl phosphite as a 2-electron donor to afford the 50-CVE complex, $\quad\left[\{\mathrm{Pt}(\right.$ bisNHC $)\}\{\mathrm{Pt}(\mathrm{bpy})\}\left\{\mathrm{RhCp}^{*}\left[\mathrm{P}(\mathrm{OEt})_{3}\right]\right\}\left(\mu_{3^{-}}\right.$ $\left.\mathrm{S})_{2}\right]^{2+}$, in which the phosphite ligand coordinates to the $\mathrm{Rh}$ center bearing a pseudo-octahedral geometry with one $\mathrm{Cp}^{*}$, two sulfido and one phosphite ligands. While the 48-CVE complex showed two reversible redox couples in a cathodic sweep in cyclic voltammetry, the 50-CVE complex exhibited a subsequent reaction of dissociation of the 
1 phosphite ligand following the 1-electron reduction to 51-

2 CVE complex. Re-oxidation of the resulted phosphine3 dissociated 49-CVE complex regenerates the 48-CVE 4 complex. These results would provide new insights of 5 reactivity and nature of metal-metal bonding in redox active 6 multinuclear complexes for utilization of such clusters as 7 redox active catalysts and molecular sensing materials.

8 Syntheses of related 48-CVE complexes with different 9 combination of metal-ligand units, $10\left[\{\mathrm{M}(\text { bisNHC })\}\{\mathrm{M}(\text { bpy })\}\left(\mathrm{M}^{\prime} \mathrm{Cp}^{*}\right)\left(\mu_{3}-\mathrm{S}\right)_{2}\right]^{2+}(\mathrm{M}=\mathrm{Pd}$ or Pt;

$11 \mathrm{M}^{\prime}=\mathrm{Rh}$ or Ir), and investigation of the details of reactions 12 with phosphite or other 2-electron donors such as $\mathrm{CO}$ to 13 elucidate the relation between metal-ligand units in 14 trinuclear complexes and their chemical and electrochemical 15 properties is in progress.

This work was partly supported by JSPS KAKENHI Grant Number JP17K05814.

Supporting Information is available on http://dx.doi.org/10.1246/cl.******.

\section{References and Notes}

1 P. Atkins, T. Overton, J. Rourke, M. Weller, F. Armstrong, in Shriver \& Atkins Inorganic Chemistry, 4th ed., Oxford University Press, Oxford, U.K., 2006, pp 557-558.

2 P. Zhao, X.-F. Liu, H.-K. Wu, J. Coord. Chem. 2017, 70, 30803094.

3 R. M. De Silva, M. J. Mays, P. R. Raithby, G. A. Solan, J. Organomet. Chem. 2002, 642, 237-245.

W. Gao, Asia J. Chem. 2015, 9, 3515-3516.

W. Gao, Asia J. Chem. 2015, 9, 3517-3518.

T. Fujimura, H. Seino, M. Hidai, Y. Mizobe, J. Organomet. Chem. 2004, 689, 738-743.

D. Masui, T. Kochi, Z. Tang, Y. Ishii, Y. Mizobe, M. Hidai, J. Organomet. Chem. 2001, 620, 69-79.

8 F.-E. Hong, S.-C. Chen, Y.-T. Tsai, Y.-C- Chang, J. Organomet. Chem. 2001, 655, 172-181.
9 F.-E. Hong, C.-P. Chang, H. Chang, Y.-L. Huang, Y.-C- Chang, J. Organomet. Chem. 2003, 677, 80-88.

10 A. R. Manning, A. J. Palmer, J. Organomet. Chem. 2002, 651, 60-65.

11 T. Kochi, Y. Nomura, Z. Tang, Y. Ishii, Y. Mizobe, M. Hidai, J. Chem. Soc., Dalton Trans. 1999, 2575-2582.

12 A. L. Eckermann, D. Fenske, T. B. Rauchfuss, Inorg. Chem. 2001, 40, 1459-1465.

13 M, Shieh, C.-H. Yu, Y.-Y. Chu, Y.-W. Guo, C.-Y. Huang, K.-J. Hsing, P.-C. Chen, C.-F. Lee, Chem. Asian J. 2013, 8, 963-973.

14 J. A. Cabeza, I. del Río, V. Riera, Organometallics, 1997, 16, $1743-1748$.

15 L.-C. Song, H.-W. Cheng, Q.-M. Hu, Z. Wang, J. Organomet. Chem. 2004, 689, 139-145.

16 T. Nishioka, K. Isobe, Chem. Lett. 1994, 1661-1664.

17 Y. Kushi, H. Nagao, T. Nishioka, K. Isobe, K. Tanaka, Chem. Lett. 1994, 2175-2178.

18 Y. Kushi, H. Nagao, T. Nishioka, K. Isobe, K. Tanaka, J. Chem. Soc., Chem. Commun. 1995, 1223-1224.

19 K. Tanaka, Y. Kushi, K. Tsuge, K. Toyohara, T. Nishioka, K. Isobe, Inorg. Chem. 1998, 37, 120-126.

20 Y. Maeda, H. Hashimoto, I. Kinoshita, T. Nishioka, Inorg. Chem. $\mathbf{2 0 1 5}, 54,448-459$.

21 Y. Maeda, H. Hashimoto, I. Kinoshita, T. Nishioka, Inorg. Chem. 2014, 53, 661-663.

22 Crystallographic data for [2] $\left(\mathrm{PF}_{6}\right)_{2}: \mathrm{C}_{29} \mathrm{H}_{35} \mathrm{~F}_{12} \mathrm{~N}_{6} \mathrm{P}_{2} \mathrm{Pt}_{2} \mathrm{RhS}_{2}, M_{\mathrm{r}}=$ 1314.77, triclinic, $P \overline{1}, a=9.547(3), b=13.220(5), c=15.519(5)$ $\AA, \alpha=78.196(12), \beta=80.820(13), \gamma=89.595(14)^{\circ}, \quad V=$ 1892.0(11) $\AA^{3}, Z=2, D_{\text {calcd }}=2.308 \mathrm{~g} \mathrm{~cm}^{-3}, 13708$ total reflections, 7927 unique $\left(R_{\text {int }}=0.0432\right), R 1=0.0434[I>2 \sigma(I)]$, $\mathrm{w} R 2=0.1234$ (all data), GOF $=1.064$. For $[3]\left(\mathrm{PF}_{6}\right)_{2} \bullet \mathrm{MeCN} \bullet$ $\mathrm{Et}_{2} \mathrm{O}: \mathrm{C}_{41} \mathrm{H}_{62} \mathrm{~F}_{12} \mathrm{~N}_{7} \mathrm{O}_{4} \mathrm{P}_{3} \mathrm{Pt}_{2} \mathrm{RhS}_{2}, M_{\mathrm{r}}=1595.09$, monoclinic, $C 2 / c$, $a=44.676(9), b=10.133(2), c=24.239(5) \AA, \beta=94.478(4)^{\circ}, V$ $=10939(4) \AA^{3}, Z=8, D_{\text {calcd }}=1.937 \mathrm{~g} \mathrm{~cm}^{-3}, 43729$ total reflections, 12481 unique $\left(R_{\text {int }}=0.0542\right), R 1=0.0315[I>2 \sigma(I)]$, $\mathrm{w} R 2=0.0653$ (all data), $\mathrm{GOF}=1.001$.

23 Crystallographic data reported in this manuscript have been deposited with Cambridge Crystallographic Data Centre as supplementary publication nos. CCDC-1936301 and -1936302. Copies of the data can be obtained free of charge via CCDC Website.

24 A. Darchen, C. Mahé, H. Patin, J. Chem. Soc., Chem. Commun. 1982, 243-245. 